\title{
Respiratory Contagion Contact
}

National Cancer Institute

\section{Source}

National Cancer Institute. Respiratory Contagion Contact. NCI Thesaurus. Code C88119.

Exposure to a suspected or confirmed infectious agent via air droplets. 